Ecology, 102(12), 2021, e03519

C 2021 The Authors. Ecology published by Wiley Periodicals LLC on behalf of Ecological Society of America

This is an open access article under the terms of the Creative Commons Attribution License, which permits use, distribution and reproduction in any medium, provided the original work is properly cited.

\title{
Functional traits driving species role in the structure of terrestrial vertebrate scavenger networks
}

Esther Sebastián-González (iD) ${ }^{1,2,48}$ Zebensui Morales-Reyes (iD) ${ }^{1}$ Francisco Botella, ${ }^{1}$ Lara Naves-Alegre (D), Juan M. Pérez-García, ${ }^{1,3}$ Patricia Mateo-Tomás (iD ${ }^{4,5}$ Pedro P. Olea (iD,${ }^{6,7}$ Marcos Moleón, ${ }^{8}$ Jomar Magalhães Barbosa (iD) ${ }^{1}$ Fernando Hiraldo, ${ }^{9}$ Eneko Arrondo, ${ }^{1,9}$ José A. Donázar, ${ }^{9}$ Ainara Cortés-Avizanda,,${ }^{9,10}$ Nuria Selva, ${ }^{11}$ Sergio A. Lambertucci, ${ }^{12}$ Aishwarya Bhattacharjee,,${ }^{13,14}$ Alexis L. Brewer, ${ }^{13,14}$ Erin F. Abernethy (iD,${ }^{15}$ Kelsey L. Turner (iD,${ }^{16}$ James C. Beasley iD 16 Travis L. DeVault iD,${ }^{16}$ Hannah C. Gerke, ${ }^{16}$ Olin E. Rhodes Jr, ${ }^{17}$ Andrés Ordiz, ${ }^{18}$ Camilla Wikenros (iD,${ }^{19}$ Barbara Zimmermann, ${ }^{20}$ Petter Wabakken, ${ }^{20}$ Christopher C. Wilmers, ${ }^{21}$ Justine A. Smith iD, 22 Corinne J. Kendall, ${ }^{23}$ Darcy Ogada, ${ }^{24}$ Ethan Frehner iD,${ }^{25}$ Maximilian L. Allen $\left(\right.$ iD,${ }^{26}$ Heiko U. Wittmer, ${ }^{27}$ James R. A. Butler, ${ }^{28}$ Johan T. du Toit (iD ${ }^{29}$ Antoni Margalida, ${ }^{3,30}$ Pilar Oliva-Vidal, ${ }^{3}$ David Wilson, ${ }^{31}$ Klemen Jerina, ${ }^{32}$ Miha Krofel $\left(i D,{ }^{32}\right.$ Rich Kostecke, ${ }^{33}$ Richard Inger, ${ }^{34}$ Esra Per,,${ }^{35,36}$ Yunus Ayhan, ${ }^{36}$ Mehmet Sanci, ${ }^{36}$ Ünsal Yilmazer, ${ }^{36}$ Akino Inagaki (iD, ${ }^{37}$ Shinsuke Koike ${ }^{\text {iD, } 37 \text { Arockianathan Samson }}$ (iD, 38 Paula L. Perrig (iD, ${ }^{12,39}$ Emma E. Spencer, ${ }^{40}$ Thomas M. Newsome id,${ }^{40}$ Marco Heurich, ${ }^{41,42}$ José D. Anadón, ${ }^{13,14,43}$ Evan R. Buechley (iD) ${ }^{44,45}$ Cayetano Gutiérrez-Cánovas, ${ }^{46}$ L. Mark Elbroch, ${ }^{47}$ and José A. SÁnchez-Zapata ${ }^{1}$

${ }^{1}$ Department of Applied Biology, Centro de Investigación e Innovación Agroalimentaria y Agroambiental (CIAGRO-UMH), Miguel Hernández University of Elche, Avenida de la Universidad s/n, Elche E-03202 Spain

${ }^{2}$ Department of Ecology, University of Alicante, Cra. San Vicente del Raspeig, Alicante E-03690 Spain

${ }^{3}$ Department of Animal Science, Faculty of Life Sciences and Engineering, University of Lleida, Lleida E-25002 Spain

${ }^{4}$ Biodiversity Research Institute, University of Oviedo-Spanish National Research Council-Principality of Asturias, Mieres E-33600 Spain

${ }^{5}$ Centre for Functional Ecology, Department of Life Sciences, University of Coimbra, Calçada Martim de Freitas, Coimbra $3000-456$ Portugal

${ }^{6}$ Departamento de Ecología, Universidad Autónoma de Madrid, Madrid E-28049 Spain

${ }^{7}$ Centro de Investigación en Biodiversidad y Cambio Global (CIBC-UAM), Universidad Autónoma de Madrid, Madrid E-28049 Spain

${ }^{8}$ Department of Zoology, University of Granada, Granada E-18071 Spain

${ }^{9}$ Department of Conservation Biology, Doñana Biological Station-CSIC, Avd. Americo Vespucio 26, Seville E-41092 Spain

${ }^{10}$ Department of Plant Biology and Ecology, Faculty of Biology, University of Seville, Avda. Reina Mercedes s/n, Seville E-41012 Spain

${ }^{11}$ Institute of Nature Conservation, Polish Academy of Sciences, Krakow PL-31-120 Poland

${ }^{12}$ Grupo de Investigaciones en Biología de la Conservación, Laboratorio Ecotono, INIBIOMA, CONICET - Universidad Nacional del Comahue, Bariloche 8400 Argentina

${ }^{13}$ Department of Biology, Queens College, City University of New York, Queens, New York 10010 USA

${ }^{14}$ Biology Program, The Graduate Center, City University of New York, New York, New York 10010 USA

${ }^{15}$ Department of Integrative Biology, Oregon State University, Corvallis, Oregon 97331 USA

${ }^{16}$ Savannah River Ecology Laboratory, Warnell School of Forestry and Natural Resources, University of Georgia, Aiken, South Carolina 29802 USA

${ }^{17}$ Savannah River Ecology Laboratory, Odum School of Ecology, University of Georgia, Aiken, South Carolina 29802 USA

${ }^{18}$ Faculty of Environmental Sciences and Natural Resource Management, Norwegian University of Life Sciences, As NO-1432 Norway

${ }^{19}$ Grimsö Wildlife Research Station, Department of Ecology, Swedish University of Agricultural Sciences, Riddarhyttan 73993 Sweden

${ }^{20}$ Faculty of Applied Ecology, Agricultural Sciences and Biotechnology, Inland Norway University of Applied Sciences, Campus Evenstad, 2318 Norway

${ }^{21}$ Center for Integrated Spatial Research, Environmental Studies Department, University of California, Santa Cruz, California 95064 USA

${ }^{22}$ Department of Wildlife, Fish, and Conservation Biology, University of California, Davis, California 95616 USA

${ }^{23}$ North Carolina Zoo, 4401 Zoo Parkway, Asheboro, North Carolina 27205 USA

${ }^{24}$ The Peregrine Fund, 5668 Flying Hawk Lane, Boise, Idaho 83709 USA

${ }^{25}$ Department of Biology, University of Utah, Salt Lake City, Utah 84112 USA

${ }^{26}$ Illinois Natural History Survey, University of Illinois, Champaign, Illinois 61801 USA

${ }^{27}$ School of Biological Sciences, Victoria University of Wellington, Wellington 6012 New Zealand

${ }^{28}$ CSIRO Land and Water, Brisbane, Queensland 4001 Australia

${ }^{29}$ Department of Wildland Resources, Utah State University, Logan, Utah 84322-5230 USA

${ }^{30}$ Institute for Game and Wildlife Research, IREC (CSIC-UCLM-JCCM), Ciudad Real E-13071 Spain

${ }^{31}$ The Biodiversity Consultancy, Cambridge CB2 ISJ United Kingdom

${ }^{32}$ Department of Forestry, Biotechnical Faculty, University of Ljubljana, Ljubljana SI-1000 Slovenia

${ }^{33} 12229$ Old Stage Trail, Austin, Texas 78750 USA

Manuscript received 7 January 2021; revised 10 May 2021; accepted 24 May 2021. Corresponding Editor: Burt P. Kotler.

${ }^{48}$ E-mail: esther.sebastian@ua.es 


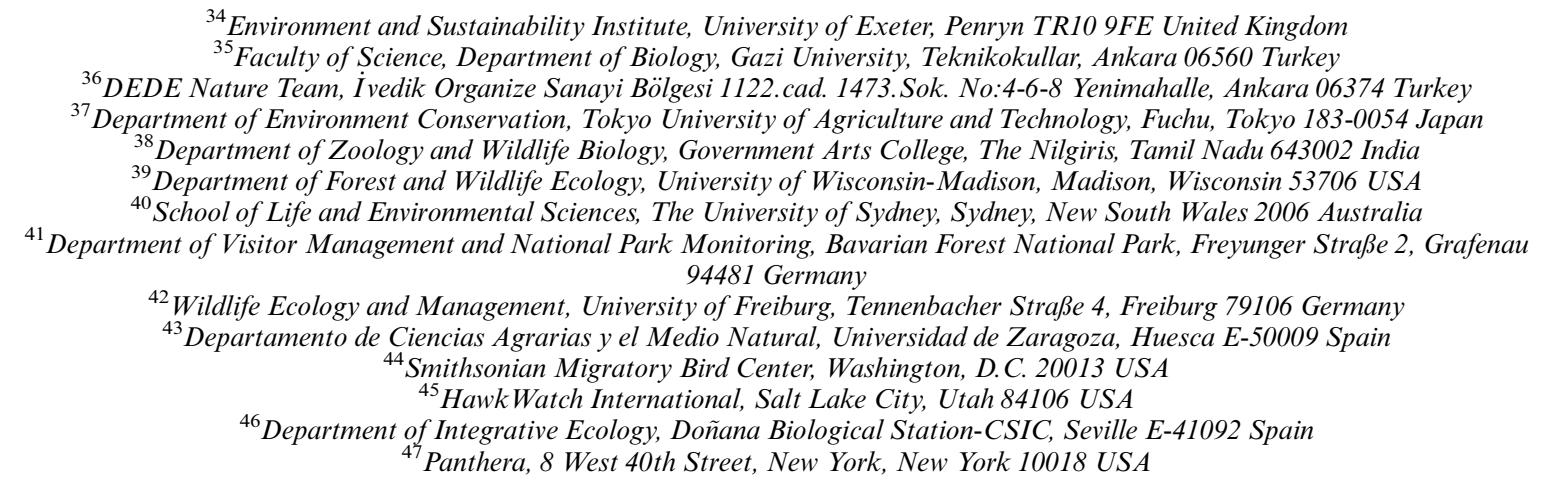

Citation: Sebastián-González, E. ,Z. Morales-Reyes, F. Botella, L. Naves-Alegre, J. M. Pérez-García, P. Mateo-Tomás, P. P. Olea, M. Moleón, J. M. Barbosa, F. Hiraldo, E. Arrondo, J. A. Donázar, A. CortésAvizanda, N. Selva, S. A. Lambertucci, A. Bhattacharjee, A. L. Brewer, E. F. Abernethy, K. L. Turner, J. C. Beasley, T. L. DeVault, H. C. Gerke, O. E. Rhodes Jr, A. Ordiz, C. Wikenros, B. Zimmermann, P. Wabakken, C. C. Wilmers, J. A. Smith, C. J. Kendall, D. Ogada, E. Frehner, M. L. Allen, H. U. Wittmer, J. R. A. Butler, J. T. du Toit, A. Margalida, P. Oliva-Vidal, D. Wilson, K. Jerina, M. Krofel, R. Kostecke, R. Inger, E. Per, Y. Ayhan, M. Sanc1, Ü. Yılmazer, A. Inagaki, S. Koike, A. Samson, P. L. Perrig, E. E. Spencer, T. M. Newsome, M. Heurich, J. D. Anadón, E. R. Buechley, C. Gutiérrez-Cánovas, L. M. Elbroch, and J. A. Sánchez-Zapata. 2021. Functional traits driving species role in the structure of terrestrial vertebrate scavenger networks. Ecology 102(12):e03519. 10.1002/ecy.3519

Abstract. Species assemblages often have a non-random nested organization, which in vertebrate scavenger (carrion-consuming) assemblages is thought to be driven by facilitation in competitive environments. However, not all scavenger species play the same role in maintaining assemblage structure, as some species are obligate scavengers (i.e., vultures) and others are facultative, scavenging opportunistically. We used a database with 177 vertebrate scavenger species from 53 assemblages in 22 countries across five continents to identify which functional traits of scavenger species are key to maintaining the scavenging network structure. We used network analyses to relate ten traits hypothesized to affect assemblage structure with the "role" of each species in the scavenging assemblage in which it appeared. We characterized the role of a species in terms of both the proportion of monitored carcasses on which that species scavenged, or scavenging breadth (i.e., the species "normalized degree"), and the role of that species in the nested structure of the assemblage (i.e., the species "paired nested degree"), therefore identifying possible facilitative interactions among species. We found that species with high olfactory acuity, social foragers, and obligate scavengers had the widest scavenging breadth. We also found that social foragers had a large paired nested degree in scavenger assemblages, probably because their presence is easier to detect by other species to signal carcass occurrence. Our study highlights differences in the functional roles of scavenger species and can be used to identify key species for targeted conservation to maintain the ecological function of scavenger assemblages.

Key words: assemblage nestedness; carrion; facilitative interaction; normalized degree; obligate scavenger; olfactory acuity; social foraging; vulture.

\section{INTRODUCTION}

How natural communities organize has interested ecologists for decades (Elton 1966). Understanding the structure of communities may reveal critical insights on their functioning, such as understanding the role of keystone species, ecological engineers, and interactions among species (Hooper et al. 2005). The species in an assemblage, however, differ in their contribution to community structure. Ecologists have recently realized that the most important species for network structure may share several key functional traits (Coux et al. 2016). For instance, in seed-dispersal assemblages, frugivorous birds play the most important network roles at a global scale (Schleuning et al. 2014). Functional traits, regarded as any property of organisms that influence performance (McGill et al. 2006), offer an ideal framework to better understand the mechanisms driving assemblage structure and how different geographic areas may be characterized by functionally similar species. This trait-based approach is especially useful in the current scenario of global environmental change, with different areas experiencing different levels of species extinction (Mouillot et al. 2013).

Scavenging is an important ecological process that facilitates the removal of carrion from the landscape (Beasley et al. 2019), thereby contributing to the recycling of nutrients and ultimately stabilizing food webs 
(Wilson and Read 2003, Wilson and Wolkovich 2011). In addition, by decreasing the time that carrion persists in the field, scavengers are regarded as pest and disease regulators (Ogada et al. 2012a, Hill et al. 2018), leading to tangible benefits to humans (Moleón et al. 2014). Among all scavenger species, terrestrial vertebrates are especially relevant because they can consume large amounts of carrion over short periods of time (DeVault et al. 2003, Mateo-Tomás et al. 2017, Morales-Reyes et al. 2017). Therefore, insights into the organization of vertebrate scavenging assemblages around carrion resources are critical to understanding their broader contribution to ecosystem processes linked to decomposition.

Scavenging assemblages can be organized following a nested structure, meaning that the species feeding on carcasses visited by few consumers are subsets of those species feeding on carcasses visited by more consumers (Selva and Fortuna 2007). Sebastián-González et al. (2016) found that vultures (i.e., obligate scavengers) can promote nestedness in scavenging communities where competition for carrion resources is large. In turn, highly nested scavenging assemblages are more efficient carrion consumers (Sebastián-González et al. 2020). Vertebrate scavenging assemblages exhibit nestedness primarily through facilitative processes, such as mammalian scavengers using cues from vultures to locate carrion (Kane and Kendall 2017), vultures benefiting from scavenging eagles by providing information on carcass location (Kane et al. 2014), mammalian predators (Jackson et al. 2020) and conspecifics (Cortés-Avizanda et al. 2014), or larger species opening up carcasses and allowing access to smaller scavengers and specialists such as bone-eaters such as bearded vultures Gypaetus barbatus (Selva et al. 2003, Moreno-Opo et al. 2016). Interspecific facilitation is especially important in scavenger assemblages because carrion is a relatively unpredictable and ephemeral food resource (DeVault et al. 2003, Cortés-Avizanda et al. 2012). However, we lack information on the functional traits that drive this facilitation process in nested vertebrate scavenger assemblages.

Recent findings have shown scavenger species with large home range sizes that are social foragers remove carcasses at higher rates than other species (GutiérrezCánovas et al. 2020). These traits are shared by most vultures and some facultative scavengers, such as large mammalian predators (e.g., lions Panthera leo and spotted hyaenas Crocuta; Gutiérrez-Cánovas et al. 2020). These species are well known to be highly efficient scavengers (Sebastián-González et al. 2016, Mateo-Tomás et al. 2017, Morales-Reyes et al. 2017). Vultures specialize in the consumption of carrion (Ruxton and Houston 2004, Cortés-Avizanda et al. 2014), and they can outcompete other vertebrates for carrion resources (Byrne et al. 2019). Other species, such as mesopredators, can also monopolize carcasses in human dominated landscapes devoid of large mammalian predators (DeVault et al. 2011, Buechley and Şekercioğlu 2016), whereas bear species Ursus spp. often monopolize carcasses in temperate and northern latitudes (e.g., Krofel et al. 2012, Allen et al. 2014).

In addition to the amount of carrion that individuals of any species can consume (Gutiérrez-Cánovas et al. 2020), each species can be important for its respective scavenger assemblage if it contributes functionally toward maintaining or influencing the assemblage structure. Indeed, a species with a driving influence on assemblage structure could make a disproportionately important contribution to scavenging efficiency (i.e., carrion consumption rate), regardless of the amount of carrion it consumes. For example, some scavengers are capable of finding and visiting most available carcasses (e.g., Elbroch et al. 2015), therefore potentially having a larger effect on the structure of their assemblage and the regulation of the scavenging function. Moreover, approaches using specieslevel network roles have already proven useful to link species function with their ecological traits (Stouffer et al. 2012, Coux et al. 2016, Llopis-Belenguer et al. 2020). Therefore, network metrics can identify which functional traits of vertebrate scavengers maintain or influence the structure of scavenging communities globally.

We used a global database consisting of 177 vertebrate scavenger species from 53 assemblages across five continents. We identified relevant functional traits that characterize those species that are critical to maintaining the structure of scavenger networks in terms of proportion of carcasses visited (i.e., the scavenging breadth, or the so-called "normalized degree" in network analyses) and how good a species is in predicting the use of the carcass by another species (i.e., "paired nested degree," AlmeidaNeto et al. 2008). We evaluated ten functional traits related to species biology and foraging ecology that are hypothesized to affect assemblage structure (Table 1). In general, we expected scavenger species with traits that enhance carcass detection and consumption, such as having a keen smell ability or being highly mobile, to have the greatest effect on assemblage structure, as they can find and exploit a larger proportion of available carcasses. We also expected species with a large paired nested degree to have traits that facilitate carcass discovery or consumption by other species, such as being vocal while foraging or being a social forager.

\section{Methods}

\section{Dataset}

We used information on 53 terrestrial vertebrate scavenger assemblages from 22 countries (see list of assemblages in Appendix S1: Table S1). These datasets include information on 177 vertebrate scavenger species (see a list of the species in Appendix S1: Table S2), including 95 birds, 75 mammals and seven reptiles from 36 different families. The scavenger species consuming herbivore carcasses were identified predominantly from 
TABLE 1. Description of the species biological and ecological traits used in this study and details on the different categories used for the classification and major hypotheses that support the use of each variable.

\begin{tabular}{|c|c|c|c|}
\hline Trait & Description & Details (and examples) & Major hypothesis \\
\hline Noisiness & $\begin{array}{l}\text { Use of } \\
\text { vocalizations }\end{array}$ & $\begin{array}{l}\text { Noisy: Species vocalizes loudly } \\
\text { while foraging (e.g., hyaenas) } \\
\text { Quiet: Species forages quietly } \\
\text { (e.g., reptiles) }\end{array}$ & $\begin{array}{l}\text { Noisy species can be used as indicators of carcass } \\
\text { presence }\end{array}$ \\
\hline Vision & Visual acuity & $\begin{array}{l}\text { High (e.g., vultures); Low } \\
\text { (e.g., wild boars) }\end{array}$ & $\begin{array}{l}\text { High visual and/or olfactory acuity can facilitate the } \\
\text { rapid location of carrion and arrival of these species can } \\
\text { be used by others as indicators of carcass presence }\end{array}$ \\
\hline Olfaction & Olfactory acuity & $\begin{array}{l}\text { High (e.g., foxes); Low (e.g., Old } \\
\text { World vultures) }\end{array}$ & $\begin{array}{l}\text { High visual and/or olfactory acuity can facilitate the } \\
\text { rapid location of carrion and arrival of these species can } \\
\text { be used by others as indicators of carcass presence }\end{array}$ \\
\hline Mobility & Mobility capacity & $\begin{array}{l}\text { Aerial: Flying species (i.e., birds) } \\
\text { Terrestrial: Non-flying species } \\
\text { (i.e. mammals and reptiles) }\end{array}$ & $\begin{array}{l}\text { Aerial mobility and larger home ranges can enable a } \\
\text { greater capacity to explore vast extents of territory and } \\
\text { find carcasses. These species can be seen by others as } \\
\text { indicators of carcass presence }\end{array}$ \\
\hline $\begin{array}{l}\text { Home } \\
\text { range }\end{array}$ & Adult home range & $\begin{array}{l}\text { Mean home range in } \mathrm{km}^{2} \\
\text { (continuous variable) }\end{array}$ & $\begin{array}{l}\text { Aerial mobility and larger home ranges can enable a } \\
\text { greater capacity to explore vast extents of territory and } \\
\text { find carcasses. These species can be seen by others as } \\
\text { indicators of carcass presence }\end{array}$ \\
\hline Sociality & Foraging behavior & $\begin{array}{l}\text { Social: Foraging in groups } \\
\text { (e.g., Gyps vultures) } \\
\text { Family: Foraging in family groups } \\
\text { (e.g., lions) } \\
\text { Solitary: Foraging alone or in pairs } \\
\text { (e.g. lynx) }\end{array}$ & $\begin{array}{l}\text { Facilitative behaviors are more common in social } \\
\text { foraging strategies. Individuals may use other more } \\
\text { conspicuous species to detect food }\end{array}$ \\
\hline Scavenging & $\begin{array}{l}\text { Scavenging } \\
\text { specialization }\end{array}$ & $\begin{array}{l}\text { Facultative: Facultative scavenger } \\
\text { (e.g., birds excluding vultures, } \\
\text { mammals, and reptiles) } \\
\text { Obligate: Obligate scavenger (i.e., } \\
\text { vultures) }\end{array}$ & $\begin{array}{l}\text { Trophic strategies showing a high degree of } \\
\text { specialization in carrion consumption such as obligate } \\
\text { scavengers, carnivorous diets or top predators are } \\
\text { present in species more adapted to carrion consumption } \\
\text { and therefore able to access and facilitate access to the } \\
\text { carrion to other more generalist species }\end{array}$ \\
\hline Predation & Predatory behavior & $\begin{array}{l}\text { Top: Top predator (e.g., brown } \\
\text { bears Ursus arctos) } \\
\text { Meso: Mesopredator (e.g., } \\
\text { raccoons Procyon lotor) } \\
\text { Non_pred: Non-predator } \\
\text { (e.g., vultures) }\end{array}$ & $\begin{array}{l}\text { Trophic strategies showing a high degree of } \\
\text { specialization in carrion consumption such as obligate } \\
\text { scavengers, carnivorous diets or top predators are } \\
\text { present in species more adapted to carrion consumption } \\
\text { and therefore able to access and facilitate access to the } \\
\text { carrion to other more generalist species }\end{array}$ \\
\hline Diet & Main diet & $\begin{array}{l}\text { Carnivorous (e.g., ocelots } \\
\text { Leopardus pardalis); Omnivorous } \\
\text { (e.g. mongooses) }\end{array}$ & $\begin{array}{l}\text { Trophic strategies showing a high degree of } \\
\text { specialization in carrion consumption such as obligate } \\
\text { scavengers, carnivorous diets or top predators are } \\
\text { present in species more adapted to carrion consumption } \\
\text { and therefore able to access and facilitate access to the } \\
\text { carrion to other more generalist species }\end{array}$ \\
\hline Body mass & Mean adult weight & $\begin{array}{l}\text { Mean adult (female and male) } \\
\text { weight in } \mathrm{kg} \text { (continuous variable) }\end{array}$ & $\begin{array}{l}\text { Larger-sized individuals are more conspicuous and more } \\
\text { easily detectable. They are also stronger and have more } \\
\text { ability to open through the carcass skin, facilitating } \\
\text { access to other species }\end{array}$ \\
\hline
\end{tabular}

the monitoring of carcasses using automatic camera traps (47 studies), but also using direct sightings from a distance or from indirect signs of scavenger interaction with the carcass $(\mathrm{N}=5$, e.g., Selva and Fortuna 2007). Carcasses were either prey remains after predator kills, fresh meat or meat that had been frozen while fresh prior to placement in the field. Each carcass was monitored continuously $(24 \mathrm{~h} / \mathrm{d})$ until it was removed by a scavenger or until its entire consumption, excluding bones and skin. Then, we identified all the vertebrate species detected consuming each carcass. Data were collected between 1991 and 2019. The final dataset included a total of 2,629 herbivore carcasses ranging from 0.07 to $150 \mathrm{~kg}$ in weight (mean \pm SD: $33.17 \pm 37.48 \mathrm{~kg}$ ) and the vertebrate scavenger species feeding on each monitored carcass. More details on the fieldwork methods and compilation of the dataset are provided in Sebastián-González et al. (2019). All data used in this study can be found at Figshare (https://doi.org/10.6084/ m9.figshare.14672250).

\section{Characterizing species contribution to network structure}

For each scavenger assemblage, we created a network matrix in which carcass $i$ was represented by rows and scavenging species $j$ by columns. Each matrix cell $a_{i j}$ indicated whether scavenger species $j$ had been detected consuming carcass $i$ or not. Using these matrixes, we 
Normalized degree

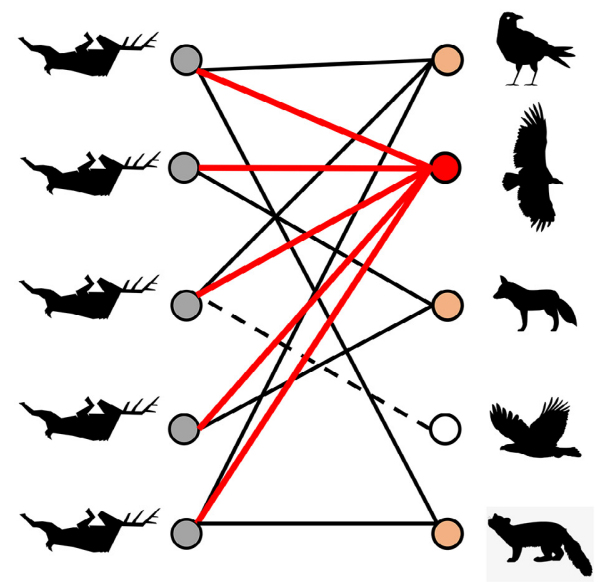

Paired nested degree

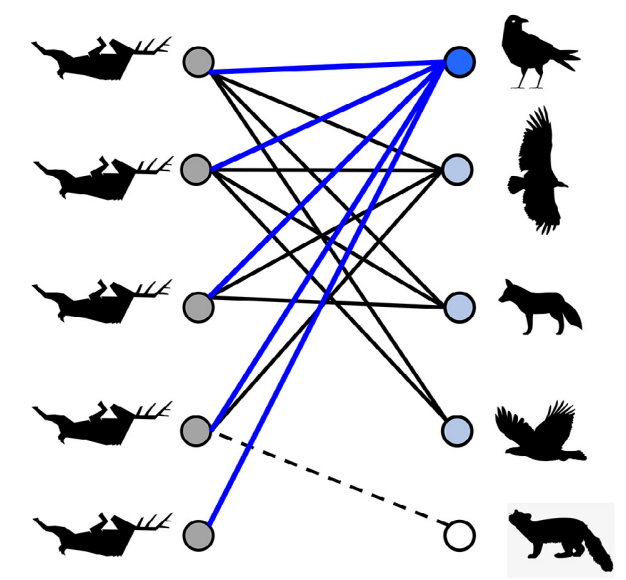

FIG. 1. Conceptual figure representing the two network metrics used: normalized degree (i.e., scavenging breadth) and paired nested degree. The normalized degree is the proportion of realized interactions calculated, while the species' paired nested degree is the average paired overlap of the species. For every pair of species, the paired overlap is the percentage of times a species appears in the same carrion than the other species. Each panel represents a scavenger assemblage where left nodes (i.e., circles) characterize individual monitored carcasses and each right node identifies a scavenger species. Lines link scavenger species consuming a specific carcass. In the left panel, the vulture has the highest degree (red node and lines) and the eagle has the lowest degree (white node and dashed line). Species with a high degree appear in the largest number of carcasses. In the right panel, the raven (blue node and lines) has the highest paired nested degree of the assemblage whereas the genet (white node and dashed line) has the lowest. Species with a high paired nested degree may establish facilitation interactions with the other species, such as signaling carcass availability or opening carcasses to allow others to feed. Silhouettes from The Noun Project https://thenounproject.com, authors: m.turan ercan, b. mijnlieff, Matt Dean, Imogen Oh, and Ricardo Moreira.

calculated two different network metrics that summarized different aspects of the contribution to network structure by each scavenger species (see Fig. 1 for a conceptual explanation of the network metrics). These metrics are related to the role of the species in the assemblage. We calculated (1) scavenging breadth as the normalized degree, defined as the proportion of realized interactions calculated as $k_{j} / S$, where $k_{j}$ (i.e., the species degree) is the total number of carcasses in which a species was detected scavenging and $S$ is the number of surveilled carcasses in the network. Species with a large normalized degree are important because they are present at most carcasses. We calculated normalized degree with the bipartite package of R (Dormann et al. 2009). Then, as most scavenger networks are nested (see Appendix S1: Table S1), we calculated (2) species' paired nested degree as the average paired overlap of the matrix columns (i.e., species) described in Almeida-Neto et al. (2008). For every pair of species in the matrix, the paired overlap is the percentage of presences in a given column that are located at an identical row in another column. The paired nested degree is the average of the paired overlaps between a focal species and all the other species in the assemblage. In a perfectly nested network, when the degree of a species $m$ (i.e., $k_{m}$ ) is lower than the degree of another species $n$ (i.e., $k_{n}$ ), the carcasses being consumed by $m$ are a subset of the carcasses consumed by $n$. Species with a high paired nested degree will follow this pattern, whereas species that deviate from the pattern will have low paired nested degree values. Species with a large paired nested degree are important because they appear in most of the carcasses in which other species appear. The paired nested degree was measured with the ANINHADO software (Guimarães and Guimarães 2006). Although normalized degree and paired nested degree are correlated (Spearman correlation coefficient $=0.67$ ), we analyzed them separately because they represent different ecological processes. The normalized degree identifies species that are present at most carcasses, measuring in some way the niche breadth for a given scavenger, i.e. on how many different carcasses can a species feed, independently of the presence or not of other scavengers at that carcass. However, species with a large paired nested degree consume most carcasses in which other species with smaller paired nested degrees appear. Therefore, the paired nested degree also measures the overlap of a given species with others in the scavenger community, e.g. how prone it could be to interact with others.

\section{Scavenger functional traits}

We compiled information on ten functional traits that could affect the ability of a scavenger species to detect, signal and consume carcasses (see the detailed description in Table 1): (1) noisiness, (2) visual and (3) olfactory acuity, (4) mobility capacity, (5) mean home range size of adults $\left(\mathrm{km}^{2}\right)$, (6) sociality in foraging behavior, (7) 
scavenging specialization (8), predatory behavior, (9) main diet, and (10) mean adult body mass $(\mathrm{kg})$. These variables may also influence the role of a species in driving the network structure. Except for body mass and home range size, we used categorical variables due to the limited information available for many species. The classification of predatory behavior (top predator, mesopredator, non-predator) was made by expert criteria of each contributing researcher in each respective study area, and therefore could vary by study system for any species. More information on how variables were defined can be found in Table 1. Even though we looked for scientific information about all the traits for each species, our database is not complete and there are some missing values. The total number of data obtained for each variable can be found in Table 2 (column N). Information comes from published data.

\section{Statistical analyses}

Our aim was to relate the network metrics (normalized degree and paired nested degree, i.e., response variables) with the species' functional traits (i.e., predictor variables). To do so, we created one database combining information from the 53 networks, where each row was a species in a network, including information on the species traits and the species network metrics in each network where the species appears. Due to some missing values describing the scavengers' functional traits, we performed statistical analyses in two steps.

First, we identified the functional traits that characterized species with a high paired nested degree and normalized degree using all data available. This allowed us to identify the importance of each species trait using the maximum information available for each of them. We did so by fitting Generalized Linear Mixed Models (GLMMs) for each of the ten predictor variables (one model for each predictor) and two random terms: species and network ID. We modeled the two network metrics separately. Normalized degree was log-transformed and modeled using a Gaussian distribution. Paired nested degree was transformed by dividing the number by 100 before modeling and fitted using a Beta distribution with the $\operatorname{glmm} T M B$ package (Brooks et al. 2017). Also, zero and one values were transformed to 0.001 and 0.999 , respectively, to fulfill the Beta distribution requirements. The only two continuous explanatory variables (i.e., body mass and home range) were logtransformed. Individuals that were not identified to species level (i.e., only identified to genus) were eliminated from the analyses. We considered that the effect of a variable received statistical support when the $95 \%$ confidence interval (CI) did not overlap zero. Then, we selected variables that received statistical support in the one-predictor models to be used in the second step. Also, because these relationships may be non-linear for the two continuous variables, we compared linear and quadratic one-predictor GLMMs for each variable using AIC-based model selection and determined whether each continuous variable should be included as quadratic in the models.

Second, we ran a model with all the variables with statistical support identified in the first step, but with only the species for which we had complete information so that models were comparable (i.e., they had the same degrees of freedom). We fitted all possible combinations and subsets of the predictor variables using the same data transformations and distributions described above. We selected all models with delta AICc $<2$ and implemented a model-averaging function with the MuMIn package (version 1.9.5; Bartoń 2013). This function averages parameter estimates across all models for each dependent variable where the respective parameter appeared, weighted by the relative importance of each model. We calculated Variance Inflation Factors (VIF) for all the explanatory variables using the car package (Fox and Weisberg 2011) to assess collinearity. "Mobility" for normalized degree and "scavenging specialization" for paired nested degree were excluded from the models because they had VIF values $>5$. We also tested

TABLE 2. Model averaged coefficients from Generalized Linear Mixed Models relating the network metrics (normalized degree and paired nested degree) of the species with the significant functional traits (i.e., those with CI not overlapping with zero) from Appendix S1: Tables S4, S5.

\begin{tabular}{lllrrr}
\hline \hline Network metric & \multicolumn{1}{c}{ Variable } & Class & Coefficient & Lower & Upper \\
\hline Normalized degree & Sociality & Social & 0.194 & -0.506 & 0.895 \\
$(\mathrm{~N}=364)$ & & Family & $\mathbf{0 . 6 2 5}$ & $\mathbf{0 . 1 5 6}$ & $\mathbf{1 . 0 9 4}$ \\
& Scavenging & Obligate & $\mathbf{1 . 4 5 1}$ & $\mathbf{0 . 8 8 2}$ & $\mathbf{2 . 0 8 0}$ \\
& Olfaction & Low & $-\mathbf{1 . 1 1 0}$ & $-\mathbf{1 . 6 4 1}$ & $-\mathbf{0 . 5 7 8}$ \\
& Diet & Omnivorous & 0.358 & -0.064 & 0.780 \\
Paired nested degree & Sociality & Family & $\mathbf{0 . 3 8 1}$ & $\mathbf{0 . 0 8 2}$ & $\mathbf{0 . 6 8 1}$ \\
N $=359)$ & & Social & $\mathbf{0 . 8 3 3}$ & $\mathbf{0 . 3 9 9}$ & $\mathbf{1 . 2 6 7}$ \\
& Log (home range) & & 0.099 & -0.027 & 0.224 \\
& Carcass weight & & $\mathbf{0 . 2 9 3}$ & $\mathbf{0 . 0 5 3}$ & $\mathbf{0 . 5 3 3}$ \\
\hline
\end{tabular}

Notes: Species and network ID are included in all models as random factors. We present the model coefficients and the $97.5 \%$ upper and $2.5 \%$ lower level confidence intervals. Models with statistical support (i.e., intervals non-overlapping with zero) are highlighted in bold. We also show the sample size of each model $(\mathrm{N})$. 
possible interactions among predictor variables by running models with all the variables plus one pairwise interaction (i.e., we run one separate model for each possible interaction). All analyses were performed in R version 3.6.2 (R Development Core Team 2019).

We also wanted to account for the potential effect of three site-specific environmental variables that are known to affect the structure of scavenger assemblages (Sebastián-González et al. 2020): (a) carcass weight (mean weight of the monitored carcasses, in $\mathrm{kg}$ ), (b) Normalized Difference Vegetation Index (NDVI), a proxy of the primary productivity and biomass; and (c) human footprint (HF), an indicator of human population pressure, human land use and infrastructure, and human access (Venter et al. 2016). HF has been calculated for two years, so we assigned to each study site the HF value closest to the date when the study was performed: $1993(\mathrm{~N}=3)$ and $2009(\mathrm{~N}=50)$. The NDVI was calculated from the MYD13Q1 V6 product (NASA Land Processes Distributed Active Archive Center). We calculated these variables within a $20-\mathrm{km}$ buffer radius around the coordinates of each study site to represent site conditions where carcasses were located. More details on the calculations of these variables and on the criteria used to select the buffer radius are provided in Sebastián-González et al. (2020). The significance and inclusion of these three variables followed the same two steps as the species traits. All continuous variables were scaled in the model.

Nestedness may be related to network size (Ulrich et al. 2009). Moreover, it is mathematically more difficult to find a nested structure in very small networks. Therefore, we reran all the analyses excluding those networks with $<20$ nodes (number of scavengers + number of carcasses), or $<7$ scavenger species (all networks had more than seven carcasses). We chose this limit because almost all networks with more than seven species were significantly nested (see Appendix S1: Table S1).

\section{Results}

The home range of the scavenger species ranged between 0.000001 and $165,514 \mathrm{~km}^{2}$ (mean: 3383.9, median: 8.12, SD: 16784.4) and the mean body mass ranged between 0.01 and $500 \mathrm{~kg}$ (mean: 11.9, median: 2, SD: 44.6). Most often, scavengers possessed good visual abilities $(91 \%)$, were solitary while foraging $(76 \%)$, and were top predators $(53 \%)$ in their respective study systems (Appendix S1: Table S3). Species differed greatly in their network values for scavenging breadth (mean: 0.25, SD: 0.25 , range: $0.005-1)$ and paired nested degree (mean: 36.4, SD: 23.2, range: 0-100).

The one-predictor GLMMs indicated that seven of the ten functional traits studied were related to species' scavenging breadth (i.e., CI not overlapping with zero, Appendix S1: Table S4; Fig. 2). Social species (i.e., species foraging in groups and/or families) had larger normalized degrees than solitary species. Obligate scavengers, as well as terrestrial scavengers with good olfactory abilities, large home ranges, and large body masses also presented higher values of scavenging breadth, as did species with an omnivorous diet. When comparing all significant variables using a modelaveraging approach, obligate scavengers, social scavengers, and species with good olfactory abilities were the taxa with highest scavenging breadths. None of the covariates (i.e., carcass weight, NDVI or human footprint; Appendix S1: Table S4) or interactions was significant.

The paired nested degree was related to four functional traits by means of one-predictor GLMMs: home range, sociality, predation, and scavenging specialization. Solitary non-predators with carnivorous diets and small home ranges showed lower paired nested degrees (Appendix S1: Table S5). When modeling all these variables together, the most important trait affecting paired nested degree was sociality, with solitary species showing the lowest degrees, species foraging in family groups showing intermediate degrees, and social scavenger taxa having the highest degrees (Table 2, Fig. 2). Species with a large home range also contributed more than those with a small home range, but the coefficient of this model overlapped zero. Sites with larger carcasses (i.e., higher carcass weight) also showed larger paired nested degree values (Table 2), but NDVI and human footprint were not significant (Appendix S1: Table S5). We did not find any significant interaction.

The results for normalized degree and paired nested degree were similar when excluding small networks (Appendix S1: Table S6). Two additional variables (body mass for normalized degree and home range for paired nested degree) affected the network role of the species. Also, there were small changes in the effect of some covariates (i.e., NDVI and carcass weight).

\section{Discussion}

Our study identifies the main functional traits that characterize vertebrate scavenger species with important roles in maintaining different aspects of network structure at a global scale. Obligate scavengers, as well as species with high olfactory acuity and social foraging behavior, had the greatest scavenging breadth (largest normalized degree) and were, therefore, the species foraging on the highest proportion of available carcasses. As measured in this study, paired nested degree identifies scavengers whose presence at a carcass is a good indicator of the presence of other species consuming the same carcass. Therefore, species with a high paired nested degree may compete with other species for the resource, but they many also be involved in the facilitative processes that promote nestedness in scavenging assemblages (Sebastián-González et al. 2016, 2019). Our analyses show that paired nested degree increased with sociality, suggesting that social foragers may facilitate carrion consumption by other species in scavenger assemblages (Sebastián-González et al. 2016, 2019). 

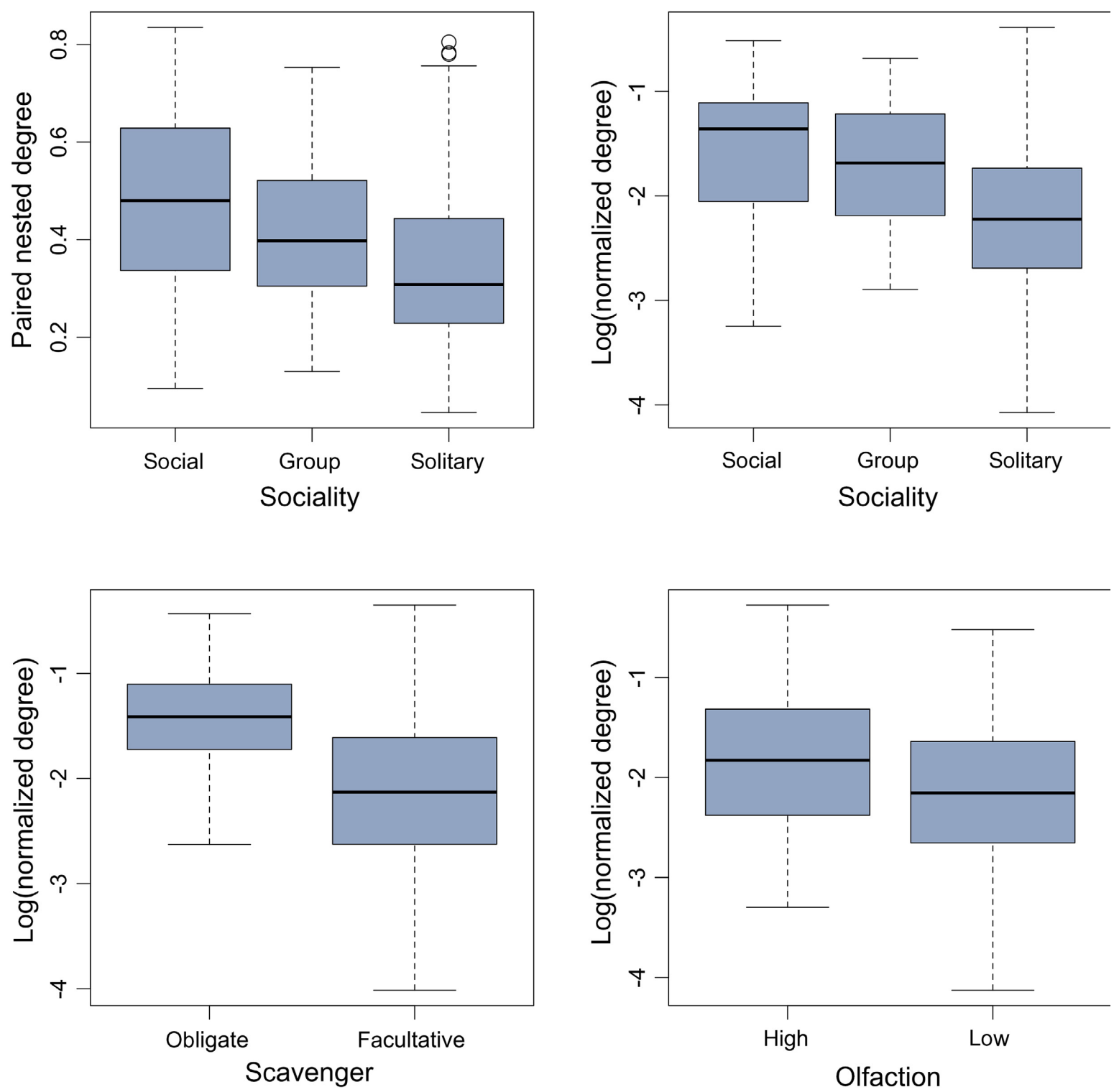

FIG. 2. Relationship between the contribution to network structure and the significant species traits from Table 2. These representations show the relationship among the predictor and response variables predicted by one-predictor models and it does not account for the effect of the other variables, as in the multivariate model in Table 2. These models include the species and network ID as random factors.

These results, based on the largest dataset compiled to date at a global scale, reinforce those of previous studies showing that the presence in an assemblage of key species, such as vultures, promoted nestedness (SebastiánGonzález et al. 2016) and that scavengers with large home ranges are more efficient carrion consumers (Gutiérrez-Cánovas et al. 2020). These functional traits can be used to identify, in any scavenging assemblage, key species that should be managed or protected to maintain or improve the ecological function of scavenging assemblages. At a local scale, other species traits are known to affect scavenging patterns, such as being a top predator in the Californian mountains (Allen et al.
2014), but the main assemblage roles can be replaced by others when these species are absent from the community.

Being social while foraging was one of the main traits describing species frequently present at many different carcasses (i.e., having a large scavenging breadth). Although it has been traditionally assumed based on field observations that social scavengers are key species in the assemblage (Selva et al. 2019), this is the first demonstration of their importance based on a large, worldwide dataset. Social scavengers include mainly vultures, corvids and canids, and other species such as spotted hyenas, lions, and wild boars Sus scrofa. Even when 
social species compete for carrion with conspecifics, this may be largely compensated by other positive effects emerging from sociality. For example, social species tend to search for and defend food collaboratively and use conspecifics as indicators of food presence (e.g., Dermody et al. 2011). When animals forage in groups, there is a higher flow of social information and therefore a higher chance of learning efficient foraging techniques from more experienced individuals (Krause and Ruxton 2002). Furthermore, group foraging may increase the dominance hierarchy, outcompeting other scavenger species (Kendall 2013). It also decreases the chances of being preyed upon, as larger groups have higher chances of detecting potential predators (Krause and Ruxton 2002, Allen and Krofel 2017). Social foraging behavior was also the most important trait of species with large paired nested degrees, which was low for solitary foragers, intermediate for family groups, and high for social species. This suggests that social scavengers facilitate carrion use for other scavengers by providing information that may be easiest to detect by other species to locate carrion. Given that carrion is an ephemeral food resource, sharing might not be negative for a species, especially when the carcass is large relative to the scavenger's body size. However, more studies are needed to fully understand the facilitation processes among heterospecific scavengers.

Even though the statistical support was weak when using the entire dataset, species with large home ranges had higher paired nested degree when excluding small networks. The differences in the results between the two datasets may be related to small assemblages having fewer large species with large home ranges. Large species are the first ones to be lost when an ecosystem is defaunated (Dirzo et al. 2014). When these species are absent, the main network roles are taken by other species. Overall, our results suggest that, when present, species with large home ranges play an important role for the nestedness of the assemblage. These species have a greater capacity to cover large areas, potentially allowing them to find and therefore signal the presence of more carcasses to other species (Ruxton and Houston 2004). As nestedness increases carrion consumption rates (Sebastián-González et al. 2016, 2020), social species with large home ranges may be key in providing scavenging functions to ecosystems (Gutiérrez-Cánovas et al. 2020). However, an understanding of how scavenging rates by social species with large home ranges changes in response to carrion availability would assist in determining their ability to influence food web dynamics around carrion.

Vultures presented consistently high scavenging breadths, as expected from the strong selective pressure for heightened food detection abilities to meet their energetic demands (Ruxton and Houston 2004). Their soaring search strategy is energetically efficient, and their visual acuity enables them to locate carrion from high altitudes, so they can forage effectively at a wider spatial scale than all other scavengers (Ruxton and Houston 2004, Byrne et al. 2019). Many vulture species also have strong beaks that can open thick-skinned carcasses, permitting access for other species (Ruxton and Houston 2004). These features increase their ability to find and consume carrion, promoting their widespread presence at the carcasses in assemblages where the species are present.

Scavengers with high olfactory acuity also had high scavenging breadths, having been observed at a relatively high proportion of carcasses. As carcass odor increases with time through decomposition, olfaction is especially important for nocturnal scavengers and for locating carcasses in densely vegetated areas. In general, mammals have high olfactory acuity and some avian scavengers such as turkey Cathartes aura, lesser yellow-headed C. burrovianus and greater yellow-headed vultures C. melambrotus, and southern caracaras Caracara plancus also use olfaction for carcass detection (Poitier 2019, Poitier et al. 2019).

Our results highlight differences in the network role played by scavenger species depending on their functional traits. However, scavenging efficiency (i.e., carcass consumption rate) depends on many factors in addition to the scavenger species present in the assemblage, such as carcass size (Moleón et al. 2015, Turner et al. 2017), season (Selva and Fortuna 2007), habitat (Smith et al. 2017, Turner et al. 2017), and human impact (SebastiánGonzález et al. 2019). As previously found for the structure of scavenger assemblages (Sebastián-González et al. 2020), carcass size influenced the role of the species in scavenging networks. Nonetheless, human footprint, which was relevant at assemblage level, did not have any effect for the species network values. Species abundance may also affect the role of a species in a network, as happens in other mutualistic and antagonistic assemblages (Vázquez et al. 2007). Abundant species may consume more carcasses just by chance than rare species. However, the effect of this variable was not tested due to the lack of data on species abundance for all study sites. Finally, the order of arrival of the species to the carrion may also affect the final structure of the assemblage, as the presence of some species may discourage or facilitate the use of the carrion by others (Jackson et al. 2020). Therefore, future studies should explicitly test the relationship between species traits, including abundance, and carrion consumption efficiency on a global scale, accounting as well for the order of arrival to the carrion.

Our results are based on two widely used network metrics, while other metrics are available, we did not use them because of several reasons. For example, Simmons et al. (2019) use motifs (subgraphs representing patterns of interactions between a small number of species) to evaluate the effect of indirect interactions of the species in a network mediated by their interaction with other species. However, our bipartite network is formed by species and carcasses, not two sets of interacting species. Carcasses are dead organic matter and cannot show 
behavioral or numeric responses that drive most types of effects. Also, many studies have evaluated the modularity of the network and the network nodes (e.g., Schleuning et al. 2014). In a preliminary test, we found that most of the networks did not show a significant modular pattern (results not shown), probably because the carcasses are relatively homogeneous within a site, and therefore modularity is not a characteristic pattern of these networks. When present, modules mostly represented some differences in the carcass settings, such as carcasses being in different microhabitats (for example, in more open vs. closed vegetation). As the identification of these differences depended more on the sampling design and they were out of the scope of the paper, we excluded the modularity analyses from the study.

We have found that species-level network metrics can be used by managers to identify species traits that affect network structure and, therefore, key species for the conservation of the scavenging function (Coux et al. 2016). This approach has already been used in other systems, such as seed dispersal (Vidal et al. 2014) and plantpollination interactions (Lázaro et al. 2019). However, there is still a big gap between the identification of key species in ecological networks and the implementation of these results in conservation programs; a gap that should be filled by better communication between ecologists and managers. In addition, given the link between network structure and ecosystem function (Peralta et al. 2014), which has also been found in scavenging assemblages (Sebastián-González et al. 2020), our findings can give new insights to predict the functional responses of scavenger assemblages to potential species extinctions in changing environments. For example, vultures (i.e., obligate scavengers) in particular, and large and social facultative scavengers, should be monitored and conserved to maintain efficient scavenging function (e.g., Ordiz et al. 2013). Many of these key scavenger species have sharply declining populations globally (Ogada et al. 2012b, Margalida and Ogada 2018), and therefore integrating their conservation policies into current and future development strategies of governments (Safford et al. 2019) and fostering social actors' positive perceptions of scavengers (Morales-Reyes et al. 2018) is essential for maintaining the valuable ecosystem service provided by scavenger assemblages.

\section{ACKNOWLEDGMENTS}

ESG, ZMR, JMB and LNA were supported by Generalitat Valenciana (SEJI/2018/024, APOSTD/2019/016, CIDEGENT/ 2020/030 and ACIF/2019/056, respectively), JMB, JMPG and CGC by Juan de la Cierva contracts (MEC; IJCI-2017-32149, FJCI-2015-25632 and IJC2018-036642-I, respectively), ACA by the Govern de les Illes Balears (PD/039/2017) and ESG and MM by Ramón y Cajal contracts (MEC; RYC-2019-027216-I, RYC-2015-19231). EA was supported by La Caixa-Severo Ochoa International PhD Program 2015. NS was partly supported by the National Science Centre in Poland (2013/08/M/ NZ9/00469 and 2016/22/Z/NZ8/00). MK and KJ were supported by the Slovenian Research Agency (P4-0059).
Contributions of HG, KLT, EFA, OER, TLD, and JCB were partially supported through funding from U.S. Department of Agriculture and the U.S. Department of Energy under (DEEM0004391) to the University of Georgia Research Foundation. HG was also supported by the Institute of Environmental Radioactivity at Fukushima University. ALB and JDA were partially supported by Queens College and the Graduate Center at the City University of New York. JDA is currently supported by a Ramón y Cajal contract (RYC-2017-22783). ERB and EF were supported by the USA National Science Foundation Graduate Research Fellowship (1256065). CK completed study with support from Hawk Mountain Sanctuary, The Peregrine Fund, and via Pompeo M. Maresi Memorial Fund via Princeton University. JAS and CCW were supported by the USA National Science Foundation \#1255913, the American Association for University Women, and the Gordon and Betty Moore Foundation. HUW acknowledges funding from the California Department of Fish \& Wildlife (P0880013). PLP was supported by the Rufford Foundation and University of WisconsinMadison. JB and JdT thank the Percy Sladen Memorial Fund and Mr Rodney Fuhr. Several authors were funded by funds from the MEC (CGL2012-40013-C02-01/02, CGL201566966-C2-1-R, CGL2015-66966-C2-1-R2, CGL2017-89905-R, RTI2018-099609-B-C21 and RTI2018-099609-B-C22) and from the Junta de Andalucía (RNM-1925). POV was supported by a research contract by the University of Lleida. EES and TMN were funded and supported by Australian Geographic, Bush Heritage Australia, Australian Academy of Sciences, Ecological Society of Australia, NSW Office of Environment and Heritage, NESP Threatened Species Recovery Hub, Emirates Wolgan Valley One and Only Resort. EP, YA, MS and UY completed study under research permit by The Republic of Turkey Ministry of Agriculture and Forestry. SAL thanks PICT (BID) 0725/2014, and IAATE. ALB and JDA would like to thank the Edmund Niles Huyck Preserve, Lyme Adirondack Forest Company, and LandVest Timberland.

\section{Literature Cited}

Allen, M. L., M. Elbroch, C. C. Wilmers, and H. U. Wittmer. 2014. Trophic facilitation or limitation? Comparative effects of pumas and black bears on the scavenger community. PLoS One 9:e102257.

Allen, M. L., and M. Krofel. 2017. Resource holding potential. Pages 1-3 in J. Vonk and T. Shackelford, editors. Encyclopedia of animal cognition and behavior. Springer International Publishing, Cham, Switzerland.

Almeida-Neto, M., P. Guimarães, P. R. Guimarães, R. D. Loyola, and W. Ulrich. 2008. A consistent metric for nestedness analysis in ecological systems: reconciling concept and measurement. Oikos 117:1227-1239.

Bartoń, K. 2013. MuMIn: Multi-model inference. R package, version 1.9.5. http://CRAN.Rproject.org/package=MuMIn

Beasley, J. C., Z. H. Olson, N. Selva, and T. L. DeVault. 2019. Ecological functions of vertebrate scavenging. Pages 125-157 in P. Olea, P. Mateo-Tomás, and J. A. Sánchez-Zapata, editors. Carrion ecology and management. Wildlife Research Monographs. Springer, Cham, Switzerland.

Brooks, M. E., K. Kristensen, K. J. van Benthem, A. Magnusson, C. W. Berg, A. Nielsen, H. J. Skaug, M. Mächler, and B. M. Bolker. 2017. glmmTMB balances speed and flexibility among packages for zero-inflated generalized linear mixed modeling. R Journal 92:378-400.

Buechley, E. R., and Ç. H. Şekercioğlu. 2016. The avian scavenger crisis: looming extinctions, trophic cascades, and loss of critical ecosystem functions. Biological Conservation 198:220-228. 
Byrne, M. E., A. E. Holland, K. L. Turner, A. L. Bryan, and J. C. Beasley. 2019. Using multiple data sources to investigate foraging niche partitioning in sympatric obligate avian scavengers. Ecosphere 10:e02548.

Cortés-Avizanda, A., R. Jovani, M. Carrete, and J. A. Donázar. 2012. Resource unpredictability promotes species diversity and coexistence in an avian scavenger guild: a field experiment. Ecology 93:2570-2579.

Cortés-Avizanda, A., R. Jovani, J. A. Donázar, and V. Grimm. 2014. Birds sky networks: How do avian scavengers search for carrion resource. Ecology 95:1799-1808.

Coux, C., R. Rader, I. Bartomeus, and J. M. Tylianakis. 2016. Linking species functional roles to their network roles. Ecology Letters 19:762-770.

Dermody, B. J., C. J. Tanner, and A. L. Jackson. 2011. The evolutionary pathway to obligate scavenging in vultures. PLoS One 6:e24635.

DeVault, T. L., Z. H. Olson, J. C. Beasley, and O. E. Rhodes Jr. 2011. Mesopredators dominate competition for carrion in an agricultural landscape. Basic and Applied Ecology 12:268-274.

DeVault, T. L., O. E. Rhodes, and J. A. Shivik. 2003. Scavenging by vertebrates: behavioural, ecological and evolutionary perspectives on an important energy transfer pathway in terrestrial ecosystems. Oikos 102:225-234.

Dirzo, R., H. S. Young, M. Galetti, G. Ceballos, N. J. B. Isaac, and B. Collen. 2014. Defaunation in the anthropocene. Science 345:401-406.

Dormann, C. F., J. Fruend, N. Bluethgen, and B. Gruber. 2009. Indices, graphs and null models: analyzing bipartite ecological networks. Open Ecology Journal 2:7-24.

Elbroch, L. M., P. E. Lendrum, M. L. Allen, and H. U. Wittmer. 2015. Nowhere to hide: pumas, black bears, and competition refuges. Behavioral Ecology 26:247-254.

Elton, C. S. 1966. The pattern of animal communities. Page 432. Methuen, London, UK.

Fox, J., and S. Weisberg. 2011. An R Companion to applied regression. Second edition. SAGE Publications, Thousand Oaks, California, USA.

Guimarães Jr, P. R., and P. Guimarães. 2006. Improving the analyses of nestedness for large sets of matrices. Environmental Modelling Software 21:1512-1513.

Gutiérrez-Cánovas, C., M. Moleón, P. Mateo-Tomás, P. P. Olea, E. Sebastián-González, and J. A. Sánchez-Zapata. 2020. Large home range scavengers support higher rates of carcass removal. Functional Ecology 34:1921-1932.

Hill, J. E., T. L. DeVault, J. C. Beasley, O. E. Rhodes Jr, and J. L. Belant. 2018. Effects of vulture exclusion on carrion consumption by facultative scavengers. Ecology and Evolution 8:2518-2526.

Hooper, D. U., et al. 2005. Effects of biodiversity on eco- system functioning: a consensus of current knowledge. Ecological Monographs 75:3-35.

Jackson, C. R., et al. 2020. A dead giveaway: foraging vultures and other avian scavengers respond to. Ecology and Evolution 10:6769-6774.

Kane, A., A. L. Jackson, D. L. Ogada, A. Monadjem, and L. McNally. 2014. Vultures acquire information on carcass location from scavenging eagles. Proceedings of the Royal Society B: Biological Sciences 281:20141072.

Kane, A., and C. J. Kendall. 2017. Understanding how mammalian scavengers use information from avian scavengers: cue from above. Journal of Animal Ecology 86:837-846.

Kendall, C. 2013. Alternative strategies in avian scavengers: how subordinate species foil the despotic distribution. Behavioral Ecology and Sociobiology 67:383-393.

Krause, J., and G. D. Ruxton. 2002. Living in groups. Oxford University Press, New York, New York, USA.
Krofel, M., I. Kos, and K. Jerina. 2012. The noble cats and the big bad scavengers: effects of dominant scavengers on solitary predators. Behavioral Ecology and Sociobiology 66:1297-1304.

Lázaro, A., C. Gómez-Martinez, D. Alomar, M. A. GonzalezEstevez, and A. Traveset. 2019. Linking species-level network metrics to flower traits and plant fitness. Journal of Ecology 108:1287-1298.

Llopis-Belenguer, C., I. Blasco-Costa, J. A. Balbuena, V. Sarabeev, and D. B. Stouffer. 2020. Native and invasive hosts play different roles in host-parasite networks. Ecography 43:559568.

Margalida, A., and D. Ogada. 2018. Old world vultures in a changing environment. Pages 457-471 in Birds of prey. Springer, Cham, Switzerland.

Mateo-Tomás, P., P. P. Olea, M. Moleón, N. Selva, and J. A. Sánchez-Zapata. 2017. Both rare and common species support ecosystem services in scavenger communities. Global Ecology and Biogeography 26:1459-1470.

McGill, B. J., B. J. Enquist, E. Weiher, and M. Westoby. 2006. Rebuilding community ecology from functional traits. Trends in Ecology and Evolution 21:178-185.

Moleón, M., J. A. Sánchez-Zapata, A. Margalida, M. Carrete, N. Owen-Smith, and J. A. Donázar. 2014. Humans and scavengers: The evolution of interactions and ecosystem services. BioScience 64:394-403.

Moleón, M., J. A. Sánchez-Zapata, E. Sebastián-González, and N. Owen-Smith. 2015. Carcass size shapes the structure and functioning of an African scavenging assemblage. Oikos 124:1391-1403.

Morales-Reyes, Z., B. Martín-López, M. Moleón, P. MateoTomás, F. Botella, A. Margalida, J. A. Donázar, G. Blanco, I. Pérez, and J. A. Sánchez-Zapata. 2018. Farmer perceptions of the ecosystem services provided by scavengers: what, who and to whom. Conservation Letters 11:e12392.

Morales-Reyes, Z., J. A. Sánchez-Zapata, E. SebastiánGonzález, F. Botella, M. Carrete, and M. Moleón. 2017. Scavenging efficiency and red fox abundance in Mediterranean mountains with and without vultures. Acta Oecologica 79:81-88.

Moreno-Opo, R., A. Trujillano, and A. Margalida. 2016. Behavioural coexistence and feeding efficiency drive niche partitioning at carcasses within the guild of European avian scavengers. Behavioral Ecology 27:1041-1052.

Mouillot, D., N. A. J. Graham, S. Villéger, N. W. H. Mason, and D. R. Bellwood. 2013. A functional approach reveals community responses to disturbances. Trends in Ecology and Evolution 28:167-177.

Ogada, D. L., M. E. Torchin, M. F. Kinnaird, and V. O. Ezenwa. 2012a. Effects of vulture declines on facultative scavengers and potential implications for mammalian disease transmission. Conservation Biology 26:453-460.

Ogada, D. L., F. Keesing, and M. Z. Virani. 2012b. Dropping dead: causes and consequences of vulture population declines worldwide. Annals of the New York Academy of Sciences 12491:57-71.

Ordiz, A., R. Bischof, and J. E. Swenson. 2013. Saving large carnivores, but losing the apex predator? Biological Conservation 168:128-133.

Peralta, G., C. M. Frost, T. A. Rand, R. K. Didham, and J. M. Tylianakis. 2014. Complementarity and redundancy of interactions enhance attack rates and spatial stability in host parasitoid food webs. Ecology 95:1888-1896.

Potier, S. 2019. Olfaction in raptors. Zoological Journal of the Linnean Society 189: 713-721.

Potier, S., O. Duriez, A. Célérier, J.-L. Liegeois, and F. Bonadonna. 2019. Sight or smell: Which senses do scavenging raptors use to find food? Animal Cognition 22:49-59. 
R Development Core Team. 2019. R: a language and environment for statistical computing. R Foundation for Statistical Computing, Vienna, Austria.

Ruxton, G. D., and D. C. Houston. 2004. Obligate vertebrate scavengers must be large soaring fliers. Journal of Theoretical Biology 228:431-436.

Safford, R., et al. 2019. Vulture conservation - the case for urgent action. Bird Conservation International 29:1-9.

Schleuning, M., et al. 2014. Ecological, historical and evolutionary determinants of modularity in weighted seeddispersal networks. Ecology Letters 17:454-463.

Sebastián-González, E., et al. 2019. Scavenging in the Anthropocene: human impact drives vertebrate scavenger species richness at a global scale. Global Change Biology 25:30053017.

Sebastián-González, E., et al. 2020. Network structure of vertebrate scavenger assemblages at the global scale: drivers and ecosystem functioning implications. Ecography 43:11431155.

Sebastian-Gonzalez, E. 2021. Functional traits driving species role in the structure of terrestrial vertebrate scavenger networks. Figshare, data set. https://doi.org/10.6084/m9.figshare. 14672250.v1

Sebastián-González, E., M. Moleón, J. P. Gibert, F. Botella, P. Mateo-Tomás, P. P. Olea, P. R. Guimarães Jr, and J. A. Sánchez-Zapata. 2016. Nested species-rich networks of scavenging vertebrates support high levels of interspecific competition. Ecology 97:95-105.

Selva, N., and M. A. Fortuna. 2007. The nested structure of a scavenger community. Proceedings of the Royal Society B 274:1101-1108.

Selva, N., B. Jedrzejewska, W. Jedrzejewski, and A. Wajrak. 2003. Scavenging on European bison carcasses in Bialowieza primeval forest (eastern Poland). Ecoscience 10:303-311.

Selva, N., M. Moleón, E. Sebastián-González, T. L. DeVault, M. M. Quaggiotto, D. M. Bailey, S. A. Lambertucci, and A.
Margalida. 2019. Vertebrate scavenging communities. Pages 71-99 in P. P. Olea, P. Mateo-Tomás, and J. A. SánchezZapata, editors. Carrion ecology and management. Springer International Publishing, Cham, Switzerland.

Simmons, B. I., A. R. Cirtwill, N. J. Baker, H. S. Wauchope, L. V. Dicks, D. B. Stouffer, and W. J. Sutherland. 2019. Motifs in bipartite ecological networks: uncovering indirect interactions. Oikos 128:154-170

Smith, J. B., L. J. Laatsch, and J. C. Beasley. 2017. Spatial complexity of carcass location influences vertebrate scavenger efficiency and species composition. Scientific Reports 7:10250.

Stouffer, D. B., M. Sales-Pardo, M. I. Sirer, and J. Bascompte. 2012. Evolutionary conservation of species' roles in food webs. Science 335:1489-1492.

Turner, K., E. Abernethy, L. M. Conner, O. E. Rhodes, and J. C. Beasley. 2017. Abiotic and biotic factors modulate carrion fate and vertebrate scavenging communities. Ecology 98:2413-2424.

Ulrich, W., M. Almeida-Neto, and N. J. Gotelli. 2009. A consumer's guide to nestedness analysis. Oikos 118:3-17.

Vázquez, D. P., C. J. Melián, N. M. Williams, N. Blüthgen, B. R. Krasnov, and R. Poulin. 2007. Species abundance and asymmetric interaction strength in ecological networks. Oikos 116:1120-1127.

Venter, O., et al. 2016. Sixteen years of change in the global terrestrial human footprint and implications for biodiversity conservation. Nature Communications 7:12558.

Vidal, M. M., E. Hasui, M. A. Pizo, J. Y. Tamashiro, W. R. Silva, and P. R. Guimarães Jr. 2014. Frugivores at higher risk of extinction are the key elements of a mutualistic network. Ecology 95:3440-3447.

Wilson, D., and J. L. Read. 2003. Kangaroo harvesters: fertilizing the rangelands. Rangeland Journal 25:47-55.

Wilson, E. E., and E. M. Wolkovich. 2011. Scavenging: how carnivores and carrion structure communities. Trends in Ecology and Evolution 26:129-135.

\section{SUPPORTING INFORMATION}

Additional supporting information may be found in the online version of this article at http://onlinelibrary.wiley.com/doi/ 10.1002/ecy.3519/suppinfo

\section{OPEN RESEARCH}

All data (Sebastián-González 2021) are available in Figshare: https://doi.org/10.6084/m9.figshare.14672250. 